\title{
Editorial: Re-visioning teaching and learning with technology in mathematics: selected papers from ICTMTI2
}

[Submitted March 2016; accepted March 2016]

The $12^{\text {th }}$ International Conference on Technology in Mathematics Teaching (ICTMT12) was hosted by the Faculty of Sciences and Technology of the University of Algarve, in the city of Faro, from 24 to 27 June 2015, and was guided by the founding spirit of the first ICTMT. Innovation, inclusion, sharing and diversity are some of the words that succinctly and suitably characterize the $12^{\text {th }}$ conference in the series. More than 120 delegates actively and enthusiastically contributed to an intense programme of scientific reports and working sessions on various topics relating to technology in mathematics teaching.

As the title of this Special Issue indicates, the overall theme of ICTMT12 was re-visioning teaching and learning with technology in mathematics and it comprised the following specific themes:

Curriculum: the use and impact of technology on the development of curricular topics across school and university levels.

Students: ways of using technology in the classroom and the influences on students' mathematics learning and outcomes.

Teachers: the teacher's role in integrating technology and trends in current teaching practices.

Resources: advances and experiences concerning the design of digital resources and software tools. Projects: technology-enhanced enrichment projects, out-of-school activities, large-scale projects and approaches to embed technology in mathematics classrooms and their significance for students' mathematics education.

All contributions published in the ICTMT12 proceedings (Amado \& Carreira, 2015) were subject to a process of peer review, led by the members of the International Scientific Committee and conducted by a sizeable pool of reviewers. Authors who presented their papers at ICTMT12 were invited to submit an enhanced version of their reported work to this TEAMAT Special Issue.

The first paper, by Helena Rocha (Portugal), focuses on teacher's knowledge for teaching mathematics with technology (KTMT), paying special attention to teachers' representational fluency. The focus is on characterizing how teachers use and integrate the different representations provided by the graphing calculator on the process of teaching and learning functions at the high school level. The conclusions reveal an active use of the graphical and algebraic representations and a scarce use of the tabular representation. The conclusions further indicate a flexible articulation between the two representations usually used. Overall, this study emphasizes teachers' KTMT and raises questions about the impact of technology on teachers' representational fluency and about the difference between a numerical and a tabular representation.

Agnaldo Esquincalha and Celina Abar (Brazil) analysed the knowledge revealed by tutors of a distance continuing education course for mathematics teachers. The authors made an adaptation of the technological pedagogical content knowledge (TPACK) theoretical framework and used it in the training of a group of course tutors. The conclusions suggest that affective and attitudinal components 
play an important role in tutoring and they propose the TPACK-OTE (TPACK-online teacher education) model to highlight the importance of these components for the training of teachers at a distance.

The research reported by Maite Mascaró, Ana Sacristán and Marta Rufino (Mexico and Portugal) addressed the teaching of experimental data analysis, probability and statistics, to university students in the environmental sciences. They present a pedagogical approach that promotes student-centred learning in a collaborative environment through computational programming-based tasks. The authors concluded that the collaborative environment facilitated the work of the students, serving as scaffold for students to overcome their fears, but also as another means of expression and clarification of the concepts under study, through both intra-team and whole-class discussions.

Daila Fonseca and Regina Franchi (Brazil) investigated an 'embodied' approach to the convergence of numerical sequences using GeoGebra. The authors present and discuss activities based on the embodiment of concepts that were applied in regular calculus classes with the use of software. The results indicate that the activities enabled the formation of a mental image of convergence when the terms are approaching a certain value, and thus elicited the embodiment of the concept of convergence and established cognitive roots for a formal definition of convergence. They also indicate that relations between different representations were established, which contributed to the abstract concept of convergence of sequences and thus to the transition from elementary to advanced mathematical thinking.

In keeping with the ICTMT spirit of providing teaching ideas, in section B Ana Breda and Santos dos Santos (Portugal) show how GeoGebra can be used to explore complex functions, using several representations obtained by the creation of new tools that complement the ones already provided by this software. These tools were designed to be used by students attending the first academic year of engineering or science courses. They can and should be used as an educational tool in collaborative learning environments. The main advantage in their use is the development of deductive reasoning and the promotion of mathematical discussions.

In sum, the set of papers in this Special Issue offer insights into the range of possibilities for the integration of technology in the teaching and learning of mathematics at the upper secondary and tertiary levels of education (including in teacher education). Such insights are an important part of re-visioning teaching and learning mathematics with technology.

NÉLIA AMADO* ${ }^{+\dagger}$

${ }^{\dagger} F C T$, University of Algarve \& UIDEF, Instituto de Educação, Universidade de Lisboa

*Email:namado@ualg.pt

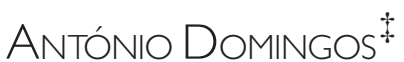

${ }^{\star}$ Faculdade de Ciências e Tecnologia da Universidade Nova de Lisboa \& Research Centre for Education and

Development (UIED)

KEITHJONES§

$\S_{\text {University of Southampton }}$

\section{REFERENCE}

Amado, N. \& Carreira, S. (eds) (2015). Proceedings of the 12th International Conference on Technology in Mathematics Teaching. Faro, Portugal: University of the Algarve. http://hdl.handle.net/10400.1/6081 